\title{
Análise Integrada da Paisagem em Trabalho de Campo no Parque Nacional de Sete Cidades (PI)
}

\author{
Integrated Landscape Analysis in Fieldwork in Parque Nacional de Sete Cidades (PI)
}

\author{
Análisis Integrada del Paisaje en Trabajo de Campo en el Parque Nacional de Sete \\ Cidades (PI)
}

Francílio de Amorim dos Santos ${ }^{1}$

\begin{abstract}
RESUMO: O estudo se propôs a caracterizar de forma integrada os aspectos físico-naturais da paisagem do Parque Nacional de Sete Cidades associado ao trabalho de campo, a partir dos elementos litológicos, geomorfológicos, climáticos, hidrográficos, pedológicos e da fisionomia da cobertura vegetal. A presente atividade constou das seguintes etapas: 1) planejamento; 2) atividades de laboratório; e 3) trabalho de campo (17 de junho de 2017). Logo, foi possível apreender que a estrutura geológica da área é predominantemente arenítica, cujas feições geomorfológicas provêm do intemperismo físico - gerando particularmente chapadas planas, mesas e escarpas abruptas -, com cotas altimétricas que variam de 128 a 279 metros e relevo de plano a suave ondulado, que ocorre em $74,4 \%$ da área. A drenagem é bastante irregular devido às condições climáticas, sendo o riacho Riachão seu principal curso fluvial. A área está sob influência da Zona de Convergência Intertropical (ZCIT), com precipitação média de 1.337 milímetros anuais e período chuvoso concentrado entre janeiro e maio. Os solos são predominantemente jovens e pouco desenvolvidos, a saber: Plintossolos e Neossolos. Esses são recobertos na maior parte por cerrado aberto latifoliado perenifólio e campo graminóide cespitoso médio em $47,42 \%$ e $35,84 \%$, respectivamente. Essas informações integram o quadro biofísico e o trabalho de campo permitiu visualiza-los à luz da abordagem sistêmica.
\end{abstract}

PALAVRAS-CHAVE: Ensino de Geografia. Abordagem integrada. Paisagem. Unidade de conservação.

ABSTRACT: The study proposed to characterize in an integrated way the physical-natural aspects of the landscape of the Parque Nacional de Sete Cidades associated to the field work, from the lithological, geomorphological, climatic, hydrographic, pedological and physiognomy elements of the vegetation cover. The present activity consisted of the following steps: 1) planning; 2) laboratory activities; 3) Fieldwork (June 17, 2017). Therefore, it was possible to understand that the geological structure of the area is predominantly arenite, whose geomorphological features come from the physical weathering - generating particularly flat plateaus, tables and abrupt escarpments - with altimetric dimensions varying from 128 to $279 \mathrm{~m}$ and flat relief to smooth occurs in $74.4 \%$ of the area.

${ }^{1}$ Instituto Federal de Educação, Ciência e Tecnologia do Piauí/Campus Piripiri, Av. Rio dos Matos, S/N, Bairro Germano. CEP: 64.260-000. Piripiri - PI. francilio.amorim@ifpi.edu.br. 
The drainage is quite irregular due to the climatic conditions, being the Riacho Riachão its main fluvial course. The area is under the influence of the Intertropical Convergence Zone (ITCZ), with an average precipitation of $1,337 \mathrm{~mm}$ per year and a rainy period concentrated between January and May. Soils are predominantly young and undeveloped, namely: Plinthsols and Neosols. These are mostly covered by open cerrado broadleaf perennial and medium cespitoso graminoid field in $47.42 \%$ and $35.84 \%$, respectively. This information is part of the biophysical framework and the fieldwork allowed visualizing it in the light of the systemic approach.

KEYWORDS: Geography teaching. Integrated approach. Landscape. Conservation unit.

RESUMEN: El estudio propuso a caracterizar de forma integrada los aspectos físico-naturales del paisaje del Parque Nacional de Siete Ciudades asociadas al trabajo de campo, a partir de los elementos litológicos, geomorfológicos, climáticos, hidrográficos, pedológicos y de la fisonomía de la cobertura vegetal. La presente actividad constó de las siguientes etapas: 1) planificación; 2) actividades de laboratorio; 3) trabajo de campo (17 de junio de 2017). Por lo tanto, fue posible aprehender que la estructura geológica del área es predominantemente arenítica, cuyas características geomorfológicas provienen del intemperismo físico - generando particularmente chapadas planas, mesas y escarpados abruptos -, con cuotas altimétricas que varían de 128 a 279 me relieve el suave ondulado que se produce en el $74,4 \%$ del área. El drenaje es bastante irregular debido a las condiciones climáticas, siendo el riacho Riachão su principal curso fluvial. El área está bajo la influencia de la Zona de Convergencia Intertropical (ZCIT), con precipitación media de 1.337 $\mathrm{mm}$ anuales y período lluvioso concentrado entre enero y mayo. Los suelos son predominantemente jóvenes y poco desarrollados, a saber: Plintossolos y Neosolos. Estos son recubiertos sobre todo por cerrado abierto latifoliado perenifolio y campo graminóide cespitoso medio en $47,42 \%$ y $35,84 \%$, respectivamente. Esta información integra el cuadro biofísico y el trabajo de campo permitió visualizarlos a la luz del enfoque sistémico.

PALABRAS CLAVES: Enseñanza de Geografía. Enfoque integrado. Paisaje. Unidad de conservación.

\section{INTRODUÇÃO}

Dentre as diversas abordagens metodológicas, distintos ramos científicos têm realizado pesquisas baseando-se na Teoria Geral dos Sistemas (TGS), que surgiu em determinado momento histórico no qual se buscava um método capaz de apreender os fenômenos de modo integrado. A TGS proposta pelo biólogo Bertalanffy (1973), teve como base a Segunda Lei da Termodinâmica, que considerou o sistema como elemento basilar e que apresentava variáveis dinâmicas e dependentes.

A TGS pode, ainda, ser definida como um conjunto de objetos ou particularidades e suas relações, articuladas para efetuar uma função específica (MENDONÇA, 1989). Esse autor explica que a Geografia Física tem buscado trabalhar sob a ótica da dialética da natureza e da análise de sistemas mostrando-se a metodologia mais adequada para embasar a produção científica da citada área do conhecimento geográfico moderno e contemporâneo. 
Nesse cenário, diversos conceitos foram apresentados como forma de subsidiar metodologicamente os estudos integrados da paisagem. Dentre esses conceitos cita-se o geossistema, proposto por Sotchava (1977), que pode ser definido como classe de sistema dinâmico e aberto, que gera mobilidade na natureza e que será ampliada quando há influência do homem. Nessa lógica, Amorim e Oliveira (2008) afirmam que o geossistema é definido como um todo sistêmico, complexo e que permite antecipar situações futuras de organização territorial.

Por sua vez, para estudos da natureza, Bertrand (1972) baseou-se no conceito de paisagem, apontando-a como o produto de uma articulação dinâmica e instável dos elementos físicos, biológicos e humanos que, interagindo dialeticamente e mutuamente uns sobre os outros, resultam numa paisagem única, indissociável e que se encontra em constante evolução.

Sobre paisagem, ressalta-se o pensamento de Santos (2008), para quem o conceito está associado a um conjunto de forma que representa uma herança histórica de realizações humanas e naturais. Nessa perspectiva, Troppmair e Galina (2006) destacam que não se pode dissociar os fatores antrópicos do estudo dos sistemas ambientais, posto que há interferência dos primeiros sobre a dinâmica e estrutura dos segundos. Guerra e Marçal (2010) compreendem a paisagem como um elemento dinâmico e, portanto, constituído por inúmeros fatores e sistemas complexos que agem ora isoladamente ora articuladamente, destacando-se o sistema humano como elemento influenciador direto ou indireto da dinâmica dos sistemas ambientais.

É importante, também, citar Tricart (1977), que em seus estudos trabalhou com o termo ecossistema, apontando-o como o estudo das relações entre os seres vivos e destes com o meio ambiente. Para ele, o sistema é o melhor instrumento para estudar os problemas ambientais, pois aplica a ele uma visão dialética, necessitando-se de uma análise em uma visão de conjunto.

Desse modo, fica evidente que a TGS vem sendo largamente utilizada pelos geógrafos físicos, pois prima por demonstrar uma interligação entre as partes, sendo o todo mais que apenas a soma das partes. Desse modo, faz-se necessário que o geógrafo, ao longo de sua formação profissional, tenha a possibilidade de integrar a teoria proposta na análise sistêmica à perspectiva do trabalho de campo, como forma de conhecer a dinâmica que perpassa os elementos que compõem a paisagem.

Nesse sentido, deve-se realçar que o trabalho de campo sempre esteve presente no caminho do geógrafo como forma de apreender os atributos da paisagem. Nesse contexto, Alentejano e Rocha-Leão (1949) destacam que o processo de sistematização da Geografia deve muito às diversas pesquisas e relatórios de campo elaborados pelos viajantes e 
naturalistas, o que resultou na construção de elementos basilares para o desenvolvimento desta ciência, particularmente ligada ao desenvolvimento do conceito de paisagem.

De acordo com Azambuja (2012) o trabalho de campo constituiu o método de estudo aplicado à Geografia Clássica, no qual se realizavam observações, descrições e explicações dos fenômenos naturais e humanos. Logo, pode-se afirmar que o olhar geográfico visa a totalidade e a dinâmica dos fenômenos naturais e humanos.

Ultimamente tem sido retomada a preocupação com a prática de atividades de campo nos cursos de Geografia, com a evolução dos estudos geográficos respaldando-se na inserção de métodos e técnicas de representação espacial (CAVALCANTI, 2011; VIADANA; CAVALCANTI, 2011). Nessa lógica, tornou-se oportuno a realização de trabalho de campo com graduandos do curso Geografia, modalidade Educação a Distância (EaD), vinculado à Universidade Federal do Piauí, com realização de análise sistêmica da paisagem e a avaliação do campo no Parque Nacional (PARNA) de Sete Cidades, situado entre os municípios de Piracuruca e Brasileira, setor norte do Piauí.

Alentejano e Rocha-Leão (1949) asseveram, ainda, que o trabalho de campo constitui situação essencial para realização da articulação entre teoria e prática, momento imprescindível para a produção do conhecimento sobre dos fenômenos geográficos, resultando em um conhecimento menos fragmentado e comprometido com as transformações socioambientais.

O trabalho de campo constitui uma forma de contato imediato do pesquisador com a realidade (SERPA, 2006) e, também, possibilita ao aluno ter contato com a realidade e, por conseguinte, uma nova dimensão do conteúdo trabalhado em sala aula (RODRIGUES; OTAVIANO, 2001). Estes autores apontam que o trabalho de campo é uma das técnicas pedagógicas mais acessíveis e eficazes que pode ser utilizada pelo professor no âmbito do processo de ensino-aprendizagem.

Reconhecendo a importância do trabalho de campo para a formação do geógrafo, Carvalho Neto e Vianna (2006) destacam que se deve utilizar o espaço geográfico como laboratório, sendo, portanto, uma ferramenta indispensável à formação do profissional e do professor de Geografia, não devendo o processo de formação ficar restrito às paredes da universidade. Deve-se reconhecer o campo como recurso didático e fonte de conhecimento, de acordo com Viadana e Cavalcanti (2011).

Nessa ótica, ressalta-se que as atividades em campo devem auxiliar no processo de ensino-aprendizagem, possibilitar ao aluno conhecer a realidade que o cerca, notadamente a ligada à paisagem local, permitir-lhe perceber as relações que se estabelecem em determinado espaço, construir um conhecimento próximo ao seu cotidiano e promover o questionamento de informações e conceitos apresentados em sala de aula (JUSTEN, 2009). 
Em suma, pode-se afirmar que o trabalho de campo compreende atividade essencial à formação docente e do pesquisador em Geografia, notadamente por permitir ao aluno deixar os muros da universidade e visualizar na prática a dinâmica que perpassa a paisagem. Nesse ponto, Viana et al. (2017) destacam que, por meio do trabalho de campo, é possível qualificar a percepção do real pelos atores envolvidos, criando a possibilidade desses indivíduos atuarem de forma crítica e construir um conhecimento mais complexo.

Por fim, cabe destacar que a pesquisa apresenta natureza descritiva quanto ao seu objetivo, que consistiu em caracterizar de forma integrada os aspectos físico-naturais da paisagem do Parque Nacional de Sete Cidades associado ao trabalho de campo, a partir dos elementos litológicos, geomorfológicos, climáticos, hidrográficos, pedológicos e da fisionomia da cobertura vegetal.

\section{ÁREA EM ESTUDO}

O PARNA de Sete Cidades está situado no norte do estado do Piauí, entre os municípios de Brasileira e Piracuruca, mais precisamente nas coordenadas geográficas: 040ㅗ'S e 04ำ15'S e 4130 W e 4145 W (Figura 1). A referida Unidade de Conservação apresenta 6.221 hectares de extensão e está delimitada por um perímetro que compreende 36,2 quilômetros (INSTITUTO BRASILEIRO DE..., 1979).

Figura 1 - Localização do Parque Nacional de Sete Cidades, situado no setor norte do Piauí

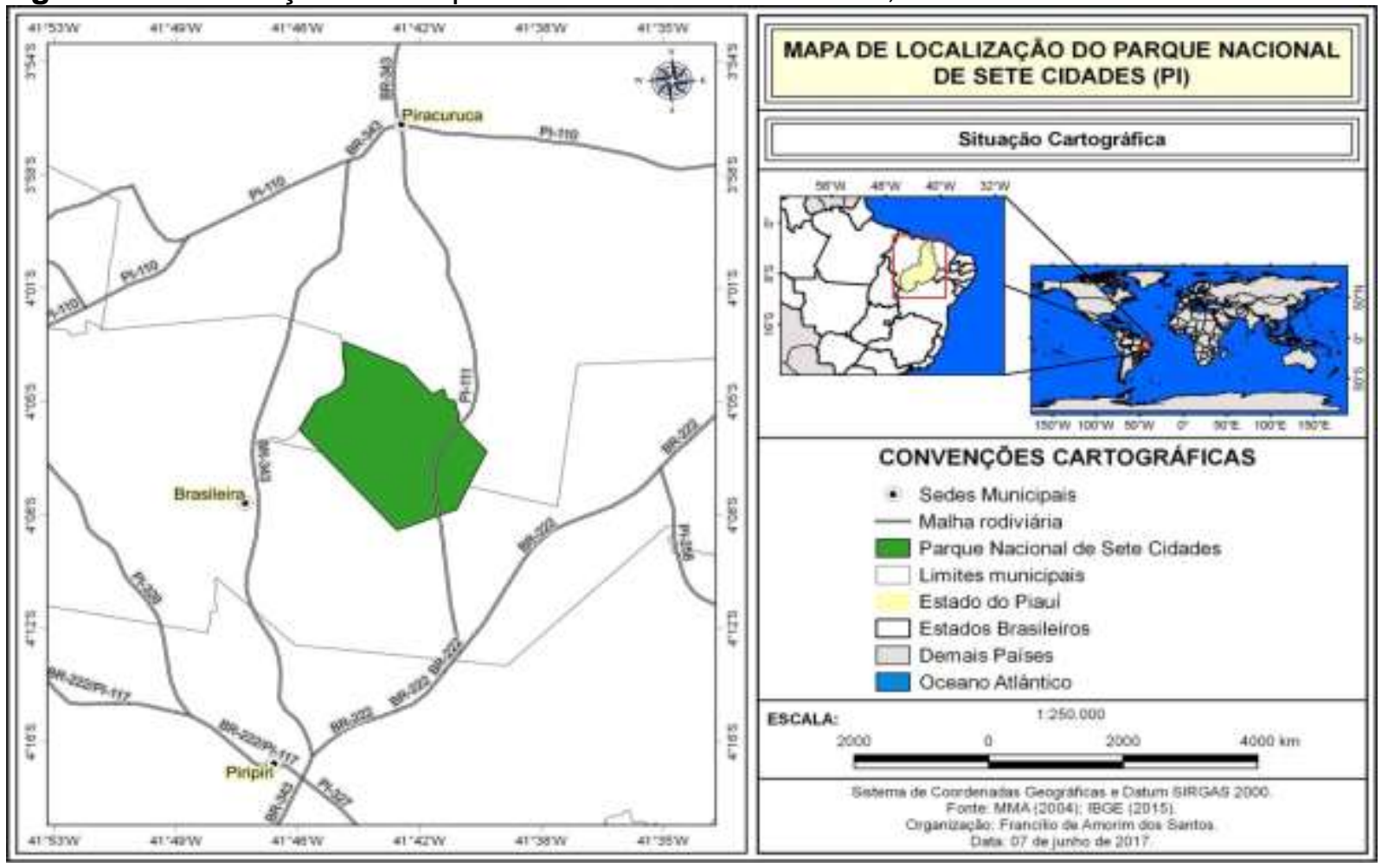

Fonte: BRASIL, 2004; IBGE, 2015. 
A área objeto de estudo foi criada via Decreto 50.744, de 08 de junho de 1961 (BRASIL, 1961). Atualmente, a referida Unidade de Conservação (UC) é administrada pelo Instituto Chico Mendes de Biodiversidade (ICMBio) e, de acordo com o Decreto no 84.017/1979, tem como objetivo principal a preservação de ecossistemas naturais englobados contra quaisquer alterações que os desvirtuem, bem como "[...] resguardar atributos excepcionais da natureza, conciliando a proteção integral da flora, da fauna e das belezas naturais, com a utilização para objetivos educacionais, recreativos e científicos" (BRASIL, 1965, p. 3), “[...] possibilitando a realização de pesquisas científicas [...] e turismo ecológico" (BRASIL, 2000, p. 14).

\section{PROCEDIMENTOS METODOLÓGICOS}

A priori, cabe salientar que a pesquisa caracterizou-se como descritiva, que corresponde ao estabelecimento de relações entre variáveis por meio da observação sistemática (GIL, 2002). Esta pesquisa esteve ligada ao uso da análise integrada como elemento basilar para conhecimento da paisagem do PARNA de Sete Cidades, perspectiva viabilizada por meio do trabalho de campo no qual, de acordo com Justen (2009), é possível perceber o espaço como um elemento dinâmico e compreender as relações existentes entre os aspectos físicos e humanos.

Nesse cenário, foi possível construir procedimentos técnicos, que foram utilizados para aprofundar o conhecimento acerca de questões propostas, tomando-se como base um planejamento inicial flexível. Para o desenvolvimento do trabalho de campo foi elaborado um roteiro metodológico que constou de três etapas (Figura 2).

Figura 2 - Roteiro metodológico para realização da análise integrada da paisagem e trabalho de campo no Parque Nacional de Sete Cidades (PI)

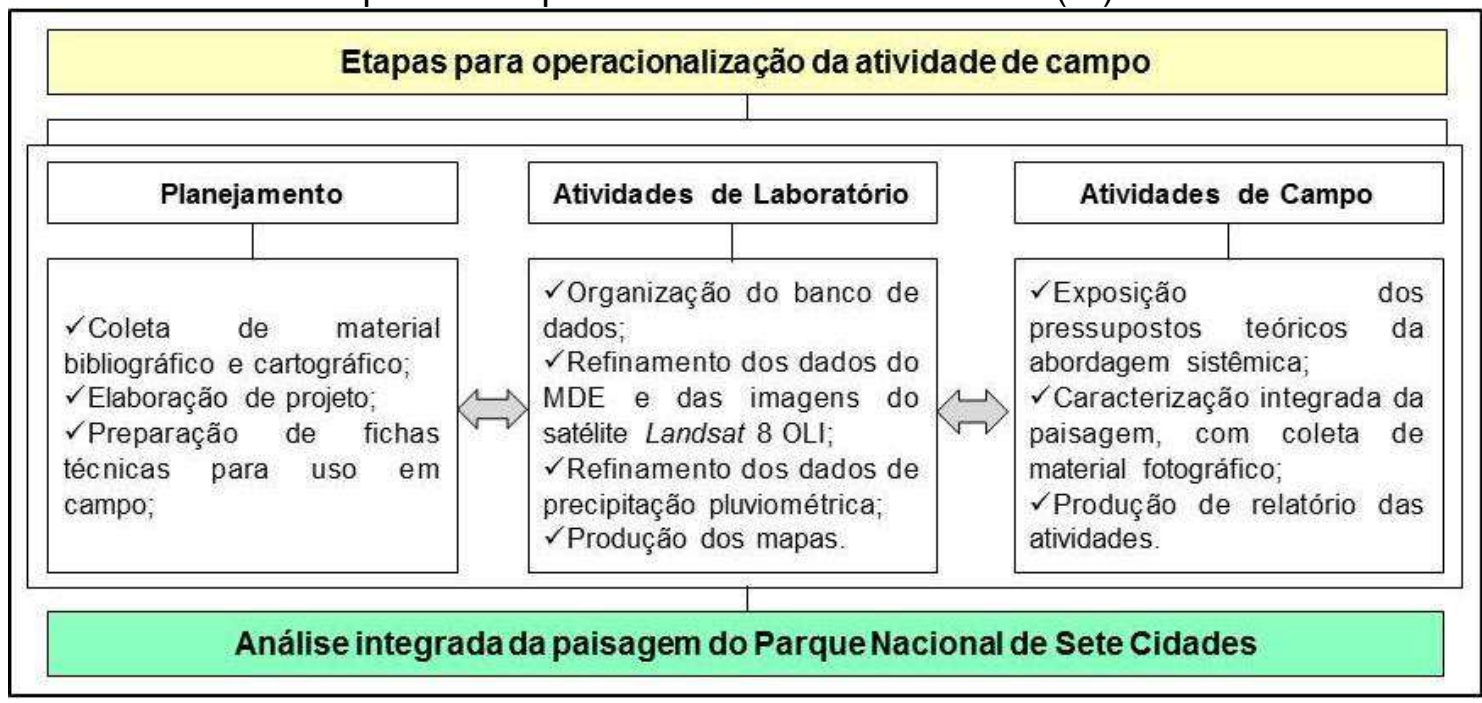


Fonte: elaborada pelo próprio autor (2017).

A primeira etapa constou do planejamento das atividades, com elaboração de projeto (levantamento bibliográfico e cartográfico) e preparação de ficha técnica para uso em campo, constando dos seguintes itens: geologia/litologia, geomorfologia (feições de dissecação e residuais), intemperismo, erosão dos solos e estado de conservação da vegetação. A essa etapa seguiu-se à ligada as atividades de laboratório, com organização do banco de dados por meio do refinamento dos dados matriciais, vetoriais e alfanuméricos.

$\mathrm{Na}$ última etapa realizou-se o trabalho de campo, no qual inicialmente efetuou-se a exposição dos pressupostos teóricos da abordagem sistêmica e características físiconaturais do PARNA. Após essa exposição foi realizado o percurso na referida UC, dia 17 de junho de 2017, com posterior exposição dos resultados em aula na semana seguinte. O foco dessa exposição deu-se na discussão acerca da importância da análise sistêmica e trabalho de campo como elementos fundamentais para conhecimento integrado da paisagem e, ainda, apresentação dos elementos da paisagem que constitui o PARNA estudado.

Deve-se enfatizar que o material gerado a partir da pesquisa bibliográfica e cartográfica foi disponibilizado aos discentes, como forma de terem o primeiro contato em relação às características físico-naturais do Parque Nacional de Sete Cidades, considerando uma visão integrada, o que foi de suma importância para o desenvolvimento de forma satisfatória e contextualizada do trabalho de campo.

O levantamento bibliográfico sobre os elementos físico-naturais do PARNA de Sete Cidades tomou como base, inicialmente, o seu respectivo Plano de Manejo. Por sua vez, os dados cartográficos (matriciais, vetoriais e alfanuméricos) utilizados foram obtidos em diversos sites, a saber:

$\checkmark$ Dados do Modelo Digital de Elevação (MDE) da Shuttle Radar Topography Mission (SRTM), com resolução espacial de 30 metros, obtidos via site do Serviço Geológico dos Estados Unidos (USGS, 2017b);

$\checkmark$ Dados de precipitação mensal de dois postos pluviométricos da Agência Nacional das Águas (ANA), considerando a série histórica de 1985 a 2016 (ANA, 2016);

$\checkmark$ Arquivo vetorial dos solos da Folha SB.24 - Jaguaribe, em escala 1:250.000, disponível no site da Infraestrutura Nacional de Dados Espaciais (INDE, 2014);

$\checkmark$ Imagem do satélite Landsat 8 sensor OLI, adquirida junto ao site) (USGS 2017a).

Para identificação das cotas altimétricas e classes de declividade do relevo utilizou-se - MDE SRTM, ao passo que para estimativa das classes de declividade do relevo considerou-se os intervalos e classes propostas pela Empresa Brasileira de Pesquisa Agropecuária (EMBRAPA, 2009), conforme é apresentado no Quadro 1. 
Quadro 1 - Intervalos e classes de Declividade média (Dm) do relevo

\begin{tabular}{|c|c|}
\hline Intervalos de Dm (\%) & Classes atribuídas \\
\hline 0 a 3 & Plano \\
\hline 3 a 8 & Suave Ondulado \\
\hline 8 a 20 & Ondulado \\
\hline 20 a 45 & Forte Ondulado \\
\hline 45 a 75 & Montanhoso \\
\hline
\end{tabular}

Fonte: Embrapa (2009).

Destaca-se, também, que se buscou fazer uma caracterização da rede de drenagem existente no contexto ambiental do PARNA estudado. Desse modo, foram elencados cinco parâmetros geométricos (Quadro 2) para tal fim, a saber: área, perímetro, fator forma da bacia, índice de circularidade e coeficiente de compacidade.

Quadro 2 - Parâmetros geométricos utilizados para análise morfométrica do Parque Nacional de Sete Cidades

\begin{tabular}{|c|c|c|c|}
\hline Parâmetro & Equação & Definição & Unidade \\
\hline Área $(A)$ & $A$ & $A=$ área da bacia $\mathrm{em} \mathrm{km}^{2}$. & $\mathrm{km}^{2}$ \\
\hline Perímetro $(P)$ & $P$ & $P=$ perímetro da bacia $\mathrm{em}^{2}$. & $\mathrm{km}^{2}$ \\
\hline $\begin{array}{c}\text { Fator forma da } \\
\text { bacia }(F f)\end{array}$ & $F f=\frac{A}{L^{2}}$ & $\begin{array}{c}A=\text { área da bacia } \mathrm{em} \mathrm{km}^{2} ; \\
L=\text { comprimento do eixo }(\mathrm{km}) .\end{array}$ & - \\
\hline $\begin{array}{c}\text { Índice de } \\
\text { circularidade }(I c)\end{array}$ & $I c=12,57 \frac{A}{p^{2}}$ & $\begin{array}{c}A=\text { área da bacia } \mathrm{em} \mathrm{km}^{2} ; \\
p=\text { perímetro da bacia }{\mathrm{em} \mathrm{km}^{2} .}^{2}\end{array}$ & - \\
\hline $\begin{array}{c}\text { Coeficiente de } \\
\text { compacidade }(K c)\end{array}$ & $K c=\frac{0,28 p}{\sqrt{A}}$ & $\begin{array}{c}A=\text { área da bacia } \mathrm{em} \mathrm{km}^{2} ; \\
P=\text { perímetro da bacia } \mathrm{em} \mathrm{km}^{2} .\end{array}$ & - \\
\hline
\end{tabular}

Fonte: Soares e Souza (2012).

Para caracterização climática da área em estudo efetuou-se o Balanço Hídrico $(\mathrm{BH})$. Foram utilizados dados das planilhas eletrônicas de dois postos pluviométricos da Agência Nacional de Águas (ANA), considerando-se série histórica de 1985 a 2016 (Quadro 3).

Quadro 3 - Dados dos postos pluviométricos utilizados para caracterização climática do Parque Nacional de Sete Cidades (PI)

\begin{tabular}{|c|c|c|c|}
\hline Nome do Posto & Latitude & Longitude & Altitude \\
\hline Piracuruca & $03^{\circ} 56^{\prime} 0.00^{\prime \prime} \mathrm{O}$ & $41^{\circ} 43^{\prime} 0.00^{\prime \prime} \mathrm{S}$ & $70 \mathrm{~m}$ \\
\hline Piripiri & $04^{\circ} 17^{\prime} 0.00^{\prime \prime} \mathrm{O}$ & $41^{\circ} 47^{\prime} 0.00^{\prime \prime} \mathrm{S}$ & $160 \mathrm{~m}$ \\
\hline
\end{tabular}

Fonte: ANA, 2017.

As falhas nos dados pluviométricos foram corrigidas via uso do programa FALHAS, pertencente ao pacote de programas USUAIS, conforme sugerem Oliveira e Sales (2016), e emprego da técnica de ponderação regional proposta por Tucci (1993). Em seguida, esses dados foram digitados em planilhas eletrônicas e espacializados no SIG QGIS por do método de interpolação IDW (peso pelo inverso da distância).

Para realização do Balanço Hídrico foram consideradas as seguintes variáveis: Precipitação média anual $(P)$, Temperatura média anual (T), Evapotranspiração potencial 
médio (ETP) e real médio (ETR), Número de meses secos (MS), Índice efetivo de umidade (Im), Índice de aridez (la), Excedente hídrico anual médio (Exc) e Déficit hídrico anual médio (Def). Ressalta-se que os dados da série histórica de 1985 a 2016 de P dos dois postos foram comparados aos da série 1912 a 1967, presente no Plano de Manejo do referido PARNA (INSTITUTO BRASILEIRO DE..., 1979).

No que diz respeito à análise da fisionomia da cobertura vegetal, foi utilizada uma imagem do sensor OLI do satélite Landsat 8, tendo as seguintes características: órbita/ponto: 219/063, com data de passagem do dia 08 de agosto de 2016. A cena foi obtida junto ao USGS e passou por procedimentos para conversão geométrica e radiométrica (16 para oito bits), via ferramentas do QGIS. Utilizou-se o estudo de Oliveira et al. (2007) como texto básico para identificar as classes de fisionomia da vegetação.

\section{RESULTADOS E DISCUSSÃO}

A área destinada ao trabalho de campo está situada no setor nordeste da Bacia do Parnaíba, considerada uma bacia intracratônica de idade paleozóica a mesozóca (BARROS; FERREIRA; PEDREIRA, 2011). Os limites do PARNA de Sete Cidades assentam-se sobre a Formação Cabeças, que possui cronologia Paleo-devoniana média a superior, esta formada por arenitos e siltitos. Os seus arenitos apresentam cores diversas, que vão desde claro a brancos e cinza-amarelados, chegando ao vermelho. Esses arenitos possuem aspecto maciço e, geralmente, estratificação cruzada (BRASIL, 1973).

De acordo com Santos (2001) os arenitos presentes nessa UC são formados por areia fina quartzosa, bem selecionada, apresentando cor amarela ou branca, conforme se pode verificar na Figura 3A. A autora relata, ainda, que ocorre mudança na granulometria nos arenitos em certas feições denominadas de "canhões" (Figura 3B), com gradação granocrescente rumo ao topo, ou seja, a base apresenta areia fina quartzosa bem selecionada passando a areia grossa subarrendada mal selecionada e conglomerado fino.

Esses arenitos apresentam-se cimentados por material silicoso e estão profundamente erodidos, notadamente pelo intemperismo físico, resultando em processo de pediplanação, com geração de chapadas planas, mesas e escarpas abruptas (INSTITUTO BRASILEIRO DE..., 1979; LOPES, 2011). De acordo Santos (2001) o PARNA de Sete Cidades apresenta quatro feições geomorfológicas: afloramentos rochosos, maciços ou esculpido em modelado ruiniforme alto e modelado ruiniforme baixo, lajeado; pavimentos de blocos; formações arenosas; e couraça ferruginosa.

De acordo com Ab'Saber (2003) Sete Cidades é considerada uma paisagem de exceção, particularmente devido a seu relevo ruiniforme, cujos aspectos físicos e ecológicos destacam-se dentre as paisagens habituais. Tal fato deve-se ao diaclasamento gerado a 
partir de movimentos tectônicos, que deixaram o relevo bastante susceptível à ação das chuvas e erosão diferencial (INSTITUTO BRASILEIRO DE..., 1979). Ressalta-se que o relevo nessa UC apresenta-se bastante dissecado, podendo-se destacar diversos morros, tais como a Serra da Descoberta (Figura 4).

Figura 3 - Arenitos do Parque Nacional de Sete Cidades (PI)
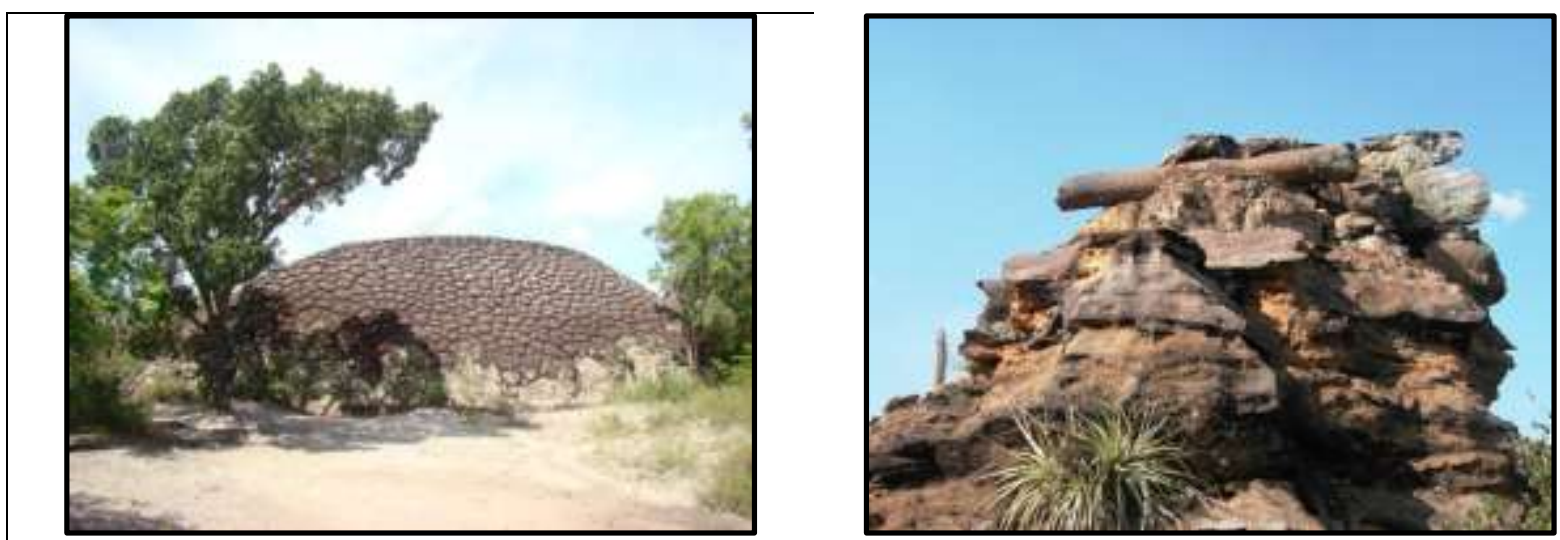

Fonte: Acervo pessoal do próprio autor (2017). Na primeira: areias finas quartzosas (neossolo quartzarênico); na segunda: mudança da granulometria do arenito (pedra dos canhões).

Figura 4 - Relevo ruiniforme, vista do mirante no Parque Nacional de Sete Cidades $(\mathrm{PI})$, ao fundo Serra da Descoberta

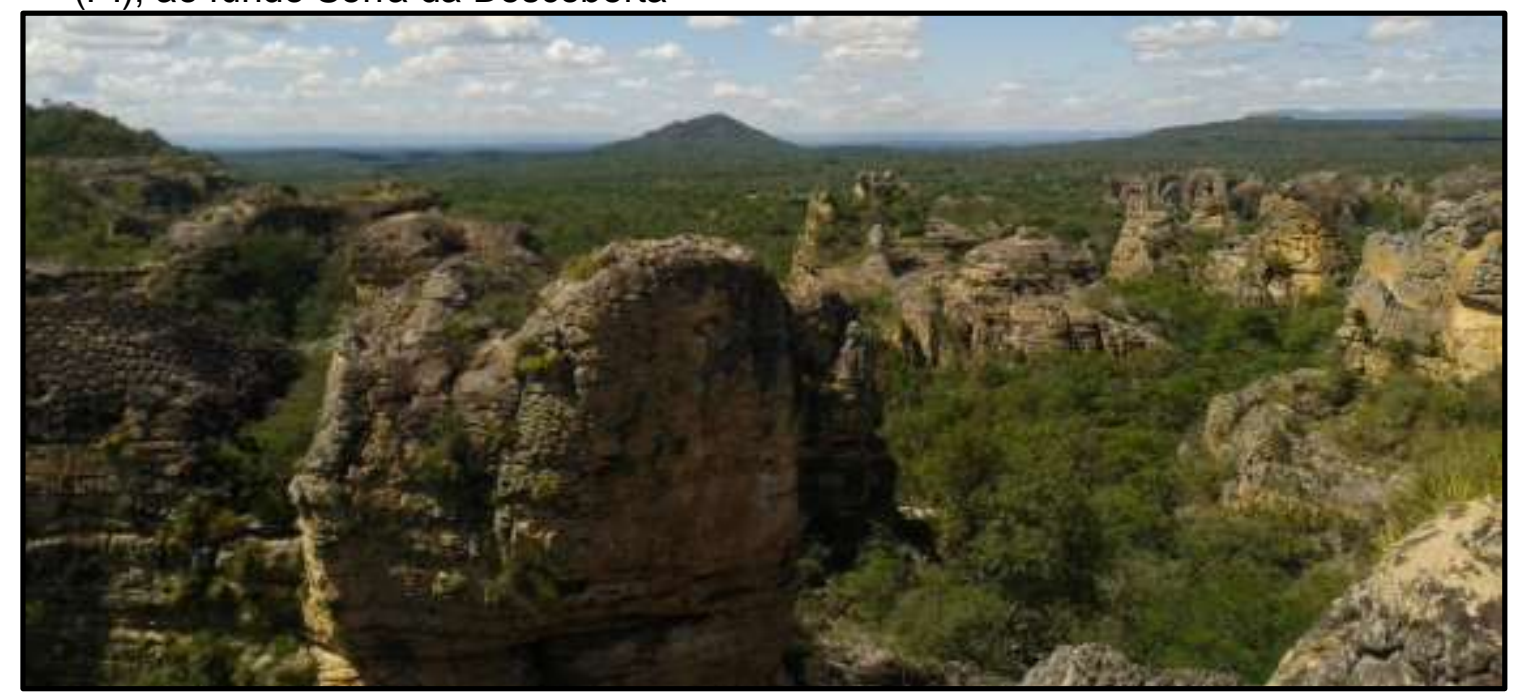

Fonte: Acervo pessoal do próprio autor (2017).

O relevo em questão é típico de bacias sedimentares, nesse caso da Bacia do Rio Parnaíba, e provém da atuação conjunta das chuvas concentradas em curto período de tempo, do clima subúmido seco, e do processo de dissecação dos cursos fluviais sobre o arenito da Formação Cabeças. Esses elementos, atuando de forma integrada, resultam em processos que tem promovido faturamento e sedimentação das rochas e, como tal, rebaixamento do relevo e desencadeamento de pedogênese. 
Nesse contexto, cabe destacar que as cotas altimétricas na área variam de 128 a 279 metros (Figura 5), com preponderância de áreas rebaixadas que variam de 158,4 a 188,7 metros $(34,5 \%)$ e 188,7 a 219,0 metros (32\%). As maiores altitudes são representadas por morros testemunhos de topos cônicos e/ou tabulares, particularmente situadas nas cotas de 249,3 a 279,6 metros, encontradas em apenas $2 \%$ do parque estudado.

Figura 5 - Classes de altimetria do relevo do Parque Nacional de Sete Cidades (PI)

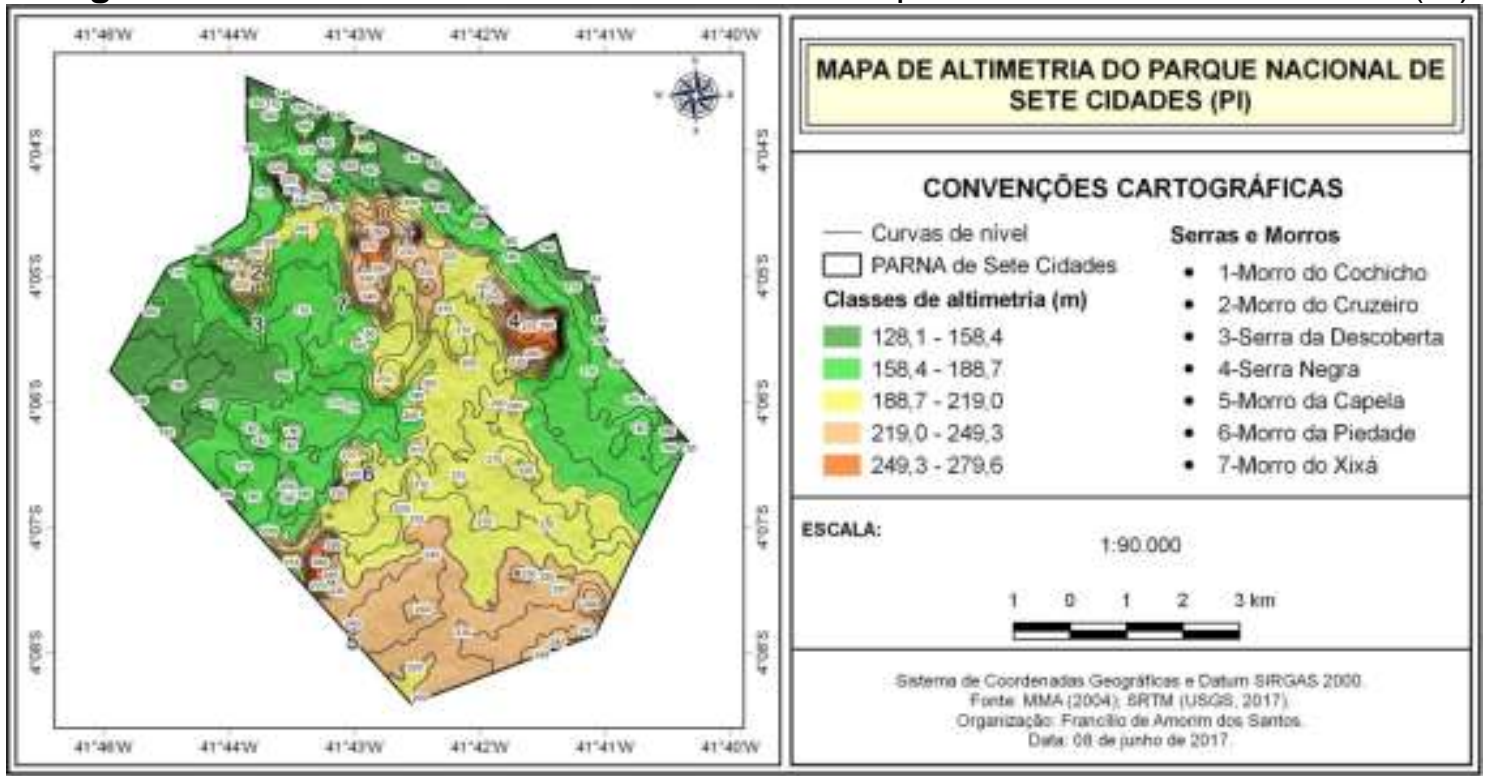

Fonte: BRASIL, 2004; USGS, 2017b.

Por sua vez, o relevo apresenta declividades que variam de plano (0 a $3 \%$ ) a montanhoso (45 a 75\%), conforme se pode visualizar na Figura 06. Ocorre predomínio de chapadas planas que formam mesas com declive suaves no reverso e escarpas abruptas. A maior parte do modelado, particularmente $74,4 \%$, possui declividades situadas entre 0 a $8 \%$ (relevo plano a suave ondulado), ao passo que o relevo forte ondulado a montanhoso foi identificado em 6,8\% do parque estudado e está diretamente ligado às serras e aos morros.

A rede de drenagem do PARNA apresenta-se bastante irregular, devido às condições climáticas atuais, com maior vazão ocorrendo a partir do mês de março, considerado o mais chuvoso. O principal curso fluvial encontrado no interior do parque diz respeito à Microbacia do Riacho Riachão (MBRR), que possui área total de 32,4 quilômetros quadrados e perímetro de 30,9 quilômetros quadrados (Quadro 4). Essa Microbacia possui fator forma $(F f)$ de valor mediano, Índice de circularidade $(I C)$ de 1,34 indicando tendência à circularidade e Coeficiente de compacidade $(K c)$ menor que 1. Nesse sentido, pode-se inferir que a MBRR apresenta elementos morfométricos que favorecem o processo de inundação.

Por meio do Balanço Hídrico $(\mathrm{BH})$ é possível observar que a precipitação média na UC é de 1.337 milímetros anuais (Tabela 01), período de 1985 a 2016, sendo possível inferir 
que houve redução nos totais pluviométricos na área, pois os mesmos dois postos exibiram $1.554 \mathrm{~mm}$ anuais, de 1912 a 1967 (INSTITUTO BRASILEIRO DE..., 1979). Contudo, devese destacar que a área não apresenta característica de clima semiárido quando considerado a variável precipitação. Deve-se ressaltar que a área estudada exibe forte influência da Zona de Convergência Intertropical (ZCIT), com período chuvoso situado entre os meses de janeiro a maio, sendo o mês de março o mais chuvoso.

Figura 6 - Classes de declividade do relevo do Parque Nacional de Sete Cidades (PI)

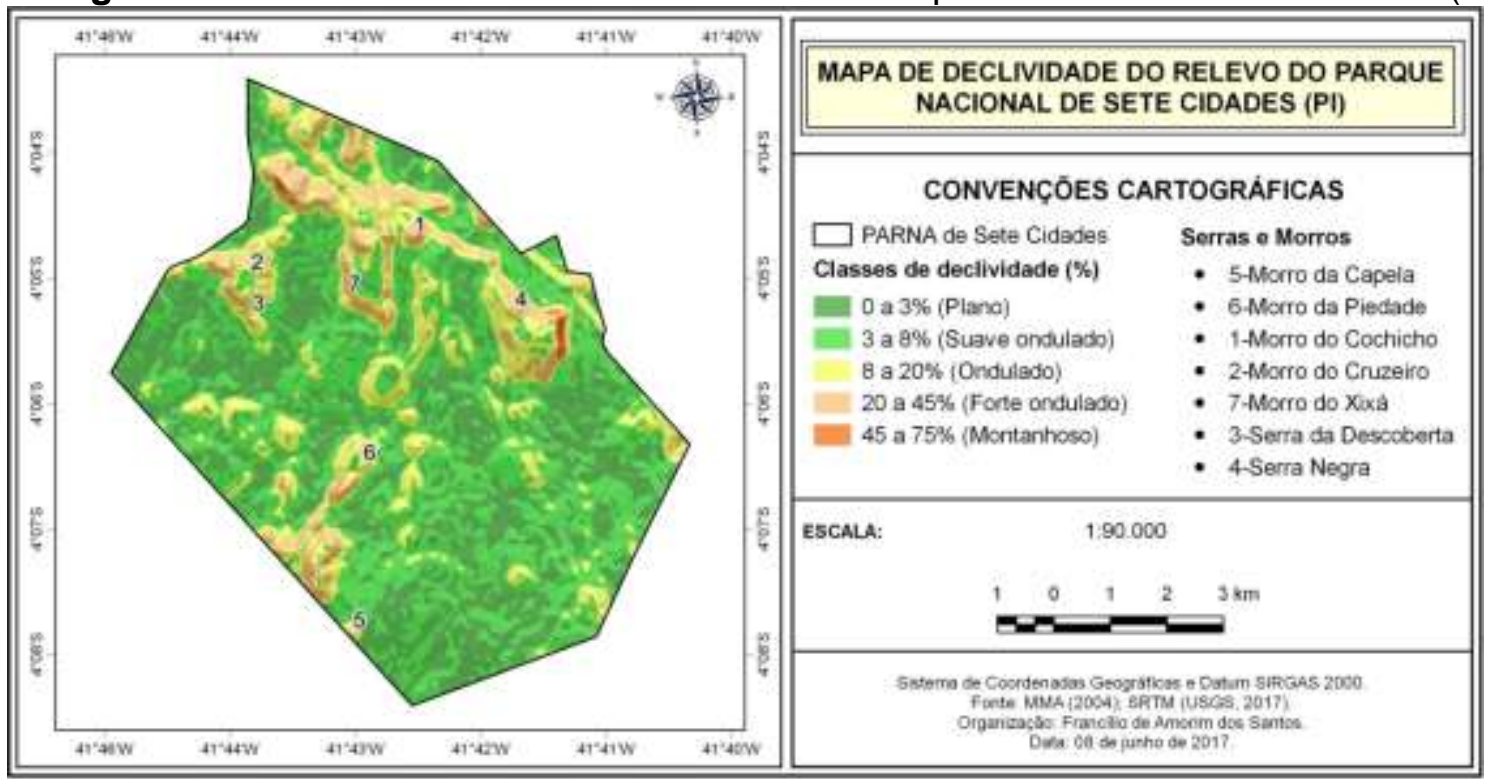

Fonte: USGS (2017b).

Quadro 4 - Parâmetros morfométricos analisados no estudo

\begin{tabular}{|c|c|c|c|}
\hline Parâmetro & Equação & Definição & Unidade \\
\hline Área $(A)$ & $A$ & $A=$ área da bacia em $\mathrm{km}^{2}$. & $\mathrm{km}^{2}$ \\
\hline Perímetro $(P)$ & $P$ & $P=$ perímetro da bacia em $\mathrm{km}^{2}$. & $\mathrm{km}^{2}$ \\
\hline Fator forma da bacia $(F f)$ & $F f=\frac{A}{L^{2}}$ & $\begin{array}{c}A=\text { área da bacia em } \mathrm{km}^{2} ; \\
L=\text { comprimento do eixo }(\mathrm{km}) .\end{array}$ & - \\
\hline Índice de circularidade $(I C)$ & Ic $=12,57 \frac{A}{p^{2}}$ & $\begin{array}{c}A=\text { área da bacia em } \mathrm{km}^{2} ; \\
p=\text { perímetro da bacia em } \mathrm{km}^{2} .\end{array}$ & - \\
\hline Coeficiente de compacidac & $K c=\frac{0,28 p}{\sqrt{A}}$ & $\begin{array}{c}A=\text { área da bacia em } \mathrm{km}^{2} ; \\
P=\text { perímetro da bacia } \mathrm{em}^{2} .\end{array}$ & - \\
\hline
\end{tabular}

Fonte: Dados da pesquisa (2018).

A temperatura anual média do PARNA é de $26,7^{\circ} \mathrm{C}$, ratificando os dados dispostos no Plano de Manejo (INSTITUTO BRASILEIRO DE..., 1979). A evapotranspiração potencial é típica de zonas de clima quente, visto que exibiu 1.602 milímetros anuais, ao passo que a evapotranspiração real foi 1.185 milímetros anuais. Por sua vez, o número de meses secos variou de 4 a 5, número baixo se comparado a outras áreas da Região Nordeste.

De acordo com a classificação climática de Thornthwaite e Mather (1955), em Sete Cidades predomina clima do tipo subúmido úmido e índice de aridez de 0,8. A relação 
existente entre o excedente e o déficit hídrico aponta que a área apresenta problemas para acumulo de água, confirmando a irregular distribuição das chuvas e/ou sua concentração ao longo do ano.

Tabela 1 - Variáveis climáticas analisadas para o Parque Nacional de Sete Cidades (PI)

\begin{tabular}{c|c|c|c}
\hline \multirow{2}{*}{ Parâmetro } & \multicolumn{3}{|c}{ Valores encontrados } \\
\cline { 2 - 4 } & Posto $1^{*}$ & Posto $2^{*}$ & Média \\
\hline Precipitação anual média $(\mathrm{mm})$ & $1202^{* *}$ & $1472^{* *}$ & $1337^{* *}$ \\
\hline Temperatura anual média $\left({ }^{\circ} \mathrm{C}\right)$ & 26,9 & 26,4 & 26,7 \\
\hline Evapotranspiração potencial médio $(\mathrm{mm})$ & 1637 & 1567 & 1602 \\
\hline Evapotranspiração real médio $(\mathrm{mm})$ & 1202 & 1168 & 1185 \\
\hline Número de meses secos & 4 & 5 & 4,5 \\
\hline Índice efetivo de umidade $(\mathrm{Im})$ & $-2,3$ & 11,3 & 4,5 \\
\hline Índice de aridez (la) & 0,73 & 0,94 & 0,8 \\
\hline Excedente hídrico anual médio $(\mathrm{mm})$ & 393 & 399 & 396 \\
\hline Déficit hídrico anual médio $(\mathrm{mm})$ & 356 & 576 & 466 \\
\hline
\end{tabular}

Fonte: Dados da pesquisa (2018). ${ }^{\star}$ Posto 1 = Piracuruca; Posto 2 = Piripiri; ${ }^{\star \star}$ ANA (2017).

As rochas de natureza sedimentar da Formação Cabeças, notadamente os arenitos, constituem substrato para atuação do processo de pedogênese. De modo geral, infere-se que os solos da área exibem vulnerabilidade natural a processos erosivos, notadamente os neossolos, que são considerados solos jovens e pouco desenvolvidos e apresentam-se mais expostos. Desse modo, o PARNA de Sete Cidades exibe duas ordens e três grandes grupos de solos (INDE, 2014):

- Plintossolos: que se caracterizam por ser compostos por material mineral, exibindo horizonte plíntico ou litoplíntico ou concrecionário, podendo começar dentro de 40 centímetros da superfície ou dentro de 200 centímetros da superfície quando precedido de horizonte glei, ou imediatamente abaixo do horizonte $A$, ou $E$, ou de outro horizonte que apresente cores pálidas, variegadas ou com mosqueados em quantidade abundante; o grande grupo identificado na área diz respeito ao Plintossolo Pétrico Concrecionário, que possui horizonte concrecionário em posição diagnóstica (EMBRAPA, 2009; INDE, 2014);

- Neossolos: considerados pouco evoluídos, constituem-se por material mineral ou orgânico, com menos de 20 centímetros de espessura, não possuindo qualquer tipo de horizonte B diagnóstico; essa ordem apresentou dois grandes grupos, a saber: Neossolo Litólico Distrófico, com saturação por bases baixa; Neossolo Quartzarênico Órtico, que não possui contato lítico dentro de 50 centímetros de profundidade (EMBRAPA, 2009; INDE, 2014).

Os dados via imagem Landsat $8 \mathrm{OLI}$ apontou que em Sete Cidades ocorrem oito classes de fisionomia da cobertura vegetal (Figura 6), sendo possível observar que predomina no parque a vegetação do tipo cerrado aberto latifoliado, que se distribui por 
47,42\% da área, seguida do campo graminóide que abrange 35,84\% da UC estudada. Outras duas classes representam as terceiras e quartas classes mais expressivas: cerrado xeromórfico e floresta ocasionalmente inundada, encontrados em 9,25\% e 6,77\% da área, respectivamente. As duas classes de maior porte são representadas pela floresta semidecídua e latifoliada perenifólia, que juntas somam apenas $0,31 \%$ do parque. A classe de solo exposto foi identificada em $0,39 \%$ da área da UC, enquanto os corpos hídricos distribuem-se por $0,02 \%$.

Diante dos dados apresentados, é possível inferir que a estrutura geológica de natureza sedimentar presente no PARNA de Sete Cidades vem sofrendo processos erosivos distintos, devido às flutuações climáticas ocorridas no Quaternário. Nesse sentido, seu modelado exibe formas ruiniformes oriundas notadamente da erosão pluvial e processos areolares, resultando em extensas áreas pedimentadas.

Esses processos erosivos resultam em distinta geodiversidade, cujo relevo apresenta diversas feições que lembram castelo e formas humanas e de animais. Diga-se, ainda, que as intempéries naturais originam solos que se apresentam pouco desenvolvidos e são substratos de diferentes fisionomias vegetacionais, que variam de campo graminóide nas áreas mais planas à floresta encontradas nas margens dos cursos fluviais e topos de morros e serras locais.

Em suma, ficou notória a importância da realização de trabalhos de campo tomando como base uma abordagem sistêmica, tendo em vista que a paisagem que se apresenta é produto da interação de diversos elementos biofísicos. Desse modo, cabe salientar que, também, a paisagem presente no PARNA de Sete Cidades é resultado de fatores externos que atuam sobre as rochas sedimentares, produzindo um relevo de particular beleza cênica, processo pedogenético que produz solos jovens e estes, por sua vez, são substratos para o crescimento de diversas fisionomias vegetais.

\section{CONSIDERAÇÕES FINAIS}

As informações supracitadas compõem o quadro biofísico e, por meio do trabalho de campo, foi possível visualizar os elementos teóricos abordados no âmbito da análise sistêmica. Diga-se, também, que as informações biofísicas ao serem apresentadas aos discentes do curso de Licenciatura em Geografia puderam subsidia-los no conhecimento. Nesse sentido, as informações supracitadas devem constituir poderosa ferramenta para a contextualização da análise sistêmica da paisagem e sensibilizar os alunos para a promoção da conservação dos atributos biofísicos presentes no PARNA de Sete Cidades e, ainda, refletir sobre a importância de realizar trabalhos de campos ao longo do aprimoramento da prática docente. 
Foi notória a necessidade e os anseios dos discentes diante do desenvolvimento do trabalho de campo, posto que a atividade constitua instrumento imprescindível ao desdobramento da prática docente e do pesquisador da ciência geográfica. O planejamento executado propôs-se a subsidiar os alunos, futuros geógrafos, de experiências que os permitisse compreenderem de forma integrada a dinâmica que perpassa a excepcional paisagem do espaço geográfico do Nordeste do Brasil. Nessa ótica, no contexto geográfico, o trabalho de campo realizado constituiu importante elemento para incentivo à produção acadêmico-científica e à disseminação de conhecimento renovado no âmbito dessa ciência.

\section{REFERÊNCIAS}

AB'SABER, A. N. Os domínios de natureza do Brasil: potencialidades paisagísticas. São Paulo: Ateliê, 2003.

ALENTEJANO, P. R. R.; ROCHA-LEÃO, O. M. Trabalho de campo: uma ferramenta essencial para os geógrafos ou um instrumento banalizado? Boletim Paulista de Geografia, São Paulo, n. 1, p. 51-67, 1949.

AMORIM, R. R.; OLIVEIRA, R. C. As unidades de paisagem como uma categoria de análise geográfica: o exemplo do município de São Vicente - SP. Sociedade \& Natureza, Uberlândia, ano 2, n. 20, p. 177-198, dez. 2008.

ANA. Agência Nacional de Águas. Hidro Web. Sistema de Informações Hidrológicas. Séries históricas: ano de 1985 a 2016. Disponível em: <http://hidroweb.ana.gov.br/>. Acesso em: 11 fev. 2017.

AZAMBUJA, L. D. Trabalho de campo e ensino de Geografia. Geosul, Florianópolis, v. 27, n. 54, p. 181-195, jul./dez. 2012.

BARROS, J. S.; FERREIRA, R. V.; PEDREIRA, A. J. Projeto geoparques: Sete Cidades PI: proposta. Brasília: Serviço Geológico do Brasil, 2011.

BERTALANFFY, L. Teoria geral dos sistemas. Petrópolis: Vozes, 1973.

BERTRAND, G. Paisagem e geografia física global: esboço metodológico. Cadernos de Ciências da Terra, São Paulo, v. 13, p. 1-27, 1972.

BRASIL. Decreto no 50.744, de 8 de junho de 1961. Cria o Parque Nacional de Sete Cidades, integrante da Seção de Parques e Florestas Nacionais do Serviço Florestal, do Ministério da Agricultura. Disponível em: <http://www2.camara.leg.br/legin/fed/decret/19601969/decreto-50744-8-junho-1961-390270-publicacaooriginal-1-pe.html>. Acesso em: 22 mar. 2018.

BRASIL. Lei no 4.771, de 15 de setembro de 1965. Institui o novo Código Florestal. Disponível em: < http://www2.camara.leg.br/legin/fed/lei/1960-1969/lei-4771-15-setembro1965-369026-publicacaooriginal-1-pl.html>. Acesso em: 22 mar. 2018.

BRASIL. Ministério de Minas e Energias. Departamento Nacional de Produção Mineral.

Projeto RADAM: levantamento dos recursos naturais. Rio de Janeiro: Ministério de Minas e Energias, 1973.

BRASIL. Ministério do Meio Ambiente. Download de dados geográficos. 2004. Disponível em: <http://mapas.mma.gov.br/i3geo/datadownload.htm>. Acesso em: 4 abr. 2016. 
BRASIL. Ministério do Meio Ambiente. Lei no 9.885, de 18 de julho de 2000. Regulamenta 0 art. 225, § 1ํㅡㄹ incisos I, II, III e VII da Constituição Federal, institui o Sistema Nacional de Unidades de Conservação da Natureza e dá outras providências. Disponível em: <http://www.planalto.gov.br/ccivil_03/Leis/L9985.htm>. Acesso em: 22 fev. 2017.

CARVALHO NETO, J. F.; VIANNA, P. C. G. O trabalho de campo e a formação do geógrafo e do professor de geografia. In: SEMINÁRIO LUSO-BRASILEIRO-CABOVERDIANO, ENCONTRO PARAIBANO DE GEOGRAFIA, 3. 2006, João Pessoa. Anais... João Pessoa, 2006. p. 1-19.

CAVALCANTI, A. P. B. Fundamentos históricos metodológicos da pesquisa de campo em Geografia. Geosul, Florianópolis, v. 26, n. 51, p. 39-58, jan./jun. 2011.

EMBRAPA. Empresa Brasileira de Pesquisa Agropecuária. Centro Nacional de Pesquisa de Solos. Sistema brasileiro de classificação de solos. Rio de Janeiro: EMBRAPA-SPI, 2009.

GIL, A. C. Como elaborar projetos de pesquisa. São Paulo: Atlas, 2002.

GUERRA, A. J. T.; MARÇAL, M. S. Geomorfologia ambiental. Rio de Janeiro: Bertrand Brasil, 2010.

IBGE. Instituto Brasileiro de Geografia e Estatística. Malha municipal digital do Brasil: situação em 2015. Rio de Janeiro: IBGE, 2015. Disponível em:

<ftp://geoftp.ibge.gov.br/malhas_digitais/>. Acesso em: 4 abr. 2016.

INDE. Infraestrutura Nacional de Dados Especiais. Mapa de solos da folha SB. 24: Jaguaribe. Escala 1:250.000. 2014. Disponível em: <http://www.visualizador.inde.gov.br/>. Acesso em: 27 nov. 2015.

INSTITUTO BRASILEIRO DE DESENVOLVIMENTO FLORESTAL. Fundação Brasileira para a Conservação da Natureza. Plano de manejo do parque nacional de Sete Cidades. Brasília, 1979.

JUSTEN, R. Importância dos trabalhos de campo na disciplina geografia: um olhar sobre a prática escolar em Ponta Grossa (PR). In: ENCONTRO NACIONAL DE PRÁTICA DE ENSINO EM GEOGRAFIA, 10., 2009, Porto Alegre. Anais... Porto Alegre: 2009. p. 1-12.

LOPES, L. S. O. Geoconservação e geoturismo no Parque Nacional de Sete Cidades, Piauí. 2011. Dissertação (Mestrado em Desenvolvimento e Meio Ambiente) - Universidade Federal do Piauí, Teresina - PI, 2011.

MENDONÇA, F. Geografia física: ciência humana? São Paulo: Contexto, 1989.

OLIVEIRA, J. G. B.; SALES, M. C. L. Usuais: programas para uso em análise ambiental. Revista Equador (UFPI), Teresina, v. 5, n. 2, p. 36 - 60, jan./jun. 2016.

OLIVEIRA, M. E. A. et al. Classes de cobertura vegetal do Parque Nacional de Sete Cidades (transição campo-floresta) utilizando imagens TM/Landsat, NE do Brasil. In: SIMPÓSIO BRASILEIRO DE SENSORIAMENTO REMOTO, 13., 2007, Florianópolis. Anais... Florianópolis, 2007. p. 1775-1783.

RODRIGUES, A. B.; OTAVIANO, C. A. Guia metodológico de trabalho de campo em geografia. Geografia, Londrina, v. 10, n. 1, p.35 - 43, jan./jun. 2001.

SANTOS, J. C. Quadro geomorfológico do Parque Nacional de Sete Cidades, Piauí. 2001. Dissertação (Mestrado em Geografia) - Universidade Federal de Santa Catarina, Centro de Filosofia e Ciências Humanas, Florianópolis, 2001.

SANTOS, M. Metamorfose do espaço habitado: fundamentos teóricos e metodológicos da geografia. São Paulo: Universidade de São Paulo, 2008.

SERPA, A. O trabalho de campo em geografia: uma abordagem teórico-metodológica.

Boletim Paulista de Geografia, São Paulo, n. 84, p. 69-76, 2006. 
SOARES, M. R. G. J.; SOUZA, J. L. M. Análise morfométrica da bacia hidrográfica do Rio Pequeno em São José dos Pinhais (PR). Revista Geografia, Londrina, v. 21, n. 1, p. 19-36, 2012.

SOTCHAVA, V. B. O estudo de geossistemas. Métodos em Questão, São Paulo, n. 6 , 1977.

THORNTHWAITE, C. W.; MATHER, J. R. The water balance. Centerton: Drexel Institute of Technology, Laboratory of Climatology, 1955.

TRICART, J. Ecodinâmica. Rio de Janeiro: IBGE, 1977.

TROPPMAIR, H.; GALINA, M. H. Geossistemas. Mercator: revista de Geografia da UFC, Fortaleza, ano 5, n. 10, p. 79-89, 2006.

TUCCI, C. E. M. Hidrologia: ciência e aplicação. Porto Alegre: UFRGS; São Paulo: USP, 1993.

USGS. United States Geological Service. Earth explorer: collection. Landsat archive.

Disponível em: <http://earthexplorer.usgs.gov>. Acesso em: 3 jun. 2017a.

USGS. United States Geological Service. Earth explorer. Digital Elevation. SRTM 1 ArcSecond Global. 2017. Disponível em: <http://earthexplorer.usgs.gov/>. Acesso em: 3 jun. 2017b.

VIADANA, A. G.; CAVALCANTI, A. P. B. Excursão geográfica didática: instrumento de prática e ensino em Geografia. Geografia, ano 9, n. 30, p. 1-18, fev. 2011.

VIANA, A. I. G. et. al. Análise geoambiental em atividade de campo no Nordeste Setentrional brasileiro: estudo de caso nos estados do Piauí e Ceará. Revista Brasileira de Geografia

Física, Recife, v. 10, n. 2, p. 597-609, 2017.

Recebido: junho de 2017. Aceito: março de 2018. 